\title{
Aproximación a la comunidad mormona de Sevilla a través de cuatro historias de vida
}

\author{
Approach to the Mormon Community in Sevilla \\ through four Life Stories
}

\author{
Rocío de Diego Cordero \\ Universidad de Sevilla*
}

\begin{abstract}
Resumen: Este trabajo muestra cómo, a través de una metodología etnográfica de las historias de vida, se llega a construir la realidad social del movimiento religioso minoritario de Jesucristo de los Santos de los Últimos Días en Sevilla. Se han realizado doce entrevistas biográficas que han permitido recoger cuatro relatos de vida de sus miembros, de los que se ha realizado trascripción y análisis. Ello se ha completado con la revisión de bibliografía propia del movimiento así como de investigadores sociales. Todo esto ha permitido conocer no sólo el camino histórico de este movimiento en Sevilla, sino la realidad social, histórica y política donde se empezó a fraguar el movimiento y todo ello unido a las vivencias personales de los informantes.
\end{abstract}

Palabras clave: Historias de vida; técnicas cualitativas; nuevos movimientos religiosos; mormones.

\begin{abstract}
This work shows how through an ethnographic methodology of the stories of life, we get to build the social reality of the minority religious movement of Jesus Christ of Latter-day Saints in Seville. There were twelve biographical interviews that allowed to collect four life stories of members after which the transcription and analysis was done. This has been completed with the revision of the movement's own literature as well as social researchers. All this has allowed us to know not only the historical path of this movement in Seville, but also the social, historical and political reality where the movement began to fuse and all this together with the personal experiences of the informants.
\end{abstract}

Keywords: Life Stories; Qualitative Techniques; New Religious Movements; Mormons.

\footnotetext{
* Recibido: 10, julio, 2017. Aceptado: 2, abril, 2018.

Email: rdediego2@us.es. Grupo de investigación PAIDI SEJ495: Pensamiento Crítico, Comunicación y Derechos Humanos.
} 


\section{INTRODUCCIÓN}

Como movimiento religioso, la Iglesia de Jesucristo de los Santos de los Últimos Días se basa en el relato de José Smith, un joven que, en respuesta a la diversidad de religiones, buscó la «religión verdadera» y fundó dicha Iglesia bajo el dictado de la revelación divina. En 1830 se organizó formalmente, se iniciaron años de persecución y finalmente se estableció en Utah la sede mundial (Hinckley, 1969).

Sus miembros llegaron a España en 1967, de la mano de militares estadounidenses y en 1970 se organizó la Primera Misión Española, aunque en lugares como Sevilla ya desde 1969 se venían produciendo reuniones en domicilios particulares alquilados para ello. En Andalucía la obra misional comenzó en Málaga y Algeciras hasta que en 1971 tuvo lugar un encuentro de miembros en Granada que supone el comienzo de la andadura de los mormones en Andalucía. En 2010, el número de miembros Santos de los Últimos Días en nuestra comunidad autónoma era de 1765 .

Dada la ausencia de bibliografía que permitiese conocer el recorrido de este movimiento religioso en la provincia de Sevilla, optamos por la técnica etnográfica de investigación cualitativa de las «historias de vida» que, al igual que la historia oral, son «espacios de contacto e influencia interdisciplinaria (...) que permiten, a través de la oralidad, aportar interpretaciones cualitativas de proceso y fenómenos histórico sociales» (Aceves, 1994: 144). De este modo podemos conocer con detalle no sólo la historia de la Iglesia sino el comportamiento de los protagonistas como miembros del grupo, mostrando a la vez una realidad universal y particular sobre este acontecimiento social.

\section{LA COMUNIDAD DE LOS SANTOS EN SEVILLA}

En Andalucía existen las estacas de Sevilla, Granada y Cádiz. ${ }^{1}$ La comunidad andaluza cuenta con aproximadamente 1765 miembros, de los cuales 1452 residen en Sevilla y provincia, y hay seis obispos: tres en la capital, el resto en municipios cercanos.

Como se ha señalado, la obra misional en Andalucía comenzó en Málaga y Algeciras, iniciada por miembros afincados en Gibraltar. En 1971 se produjo un encuentro de miembros en Granada, lo que supuso un impulso a la andadura mormona en Andalucía. Sevilla se encuentra entre las provincias con mayor número

1 Estaca: Los miembros de la iglesia se agrupan por barrios o ramas (si son grupos pequeños) que están organizados geográficamente. A su vez, un grupo de barrios forma una estaca. 
de miembros, repartidos en 2 barrios y 3 ramas; superada por Cádiz, la más prolífica, con 8 comunidades y Málaga con 7 . Así hasta un total de 26 congregaciones en Andalucía (Briones, 2010).

Tras el trabajo etnográfico realizado con esta comunidad durante más de dos años, se evidencia que en Andalucía y en Sevilla (salvo el barrio de Fuengirola, en el que hay miembros jubilados ingleses), los barrios lo forman españoles e inmigrantes latinoamericanos, solteros y familias, que conocen la iglesia principalmente por transmisión familiar, aunque también hay un número de conversos que cada año se une a la iglesia gracias a la obra misional que se lleva a cabo en nuestra comunidad autónoma. Los rangos de edad son muy variados, no se parecía un rol/estatus social-económico-cultural generalizado, sino que prevalece la diversidad entre los miembros. Generalmente, los miembros acuden a los centros que les corresponden según el lugar en el que residen, aunque hay familias que tienen que desplazarse a veces distancias medias. Se presenta a continuación la distribución de los miembros por barrios y el porcentaje sobre la población total.

\begin{tabular}{|lccc|}
\hline \multicolumn{1}{|c|}{ Localización } & Población total & Población SUD & $\begin{array}{c}\text { \% Población SUD sobre } \\
\text { Población total }\end{array}$ \\
\hline Sevilla 1, 2 & 704198 & $348+464$ & $0,11 \%$ \\
Castilleja de la Cuesta & 17282 & 214 & $1,24 \%$ \\
Dos hermanas & 125086 & 217 & $0,17 \%$ \\
Alcalá de Guadaira & 71740 & 209 & $0,29 \%$ \\
Total & 918306 & 1452 & $0,16 \%$ \\
\hline
\end{tabular}

\section{METODOLOGÍA}

Para tratar la historia de la iglesia mormona en Sevilla optamos por un estudio cualitativo, y para ello utilizamos la técnica de las «historias de vida», por considerarla la más adecuada para conocer realmente las características de esta realidad social.

Con historias de vida nos referimos a relatos contados en primera persona por participantes de un mismo hecho social. Para llevarlas a cabo se realizó un trabajo previo de documentación del movimiento en el que se delimitaron claramente los objetivos de la investigación, así como numerosos acercamientos al campo, seguidos de entrevistas a muchos de los miembros, lo que permitió no sólo un conocimiento amplio del objeto de estudio sino que contribuyó a la adecuada selección de los informantes. 
Los entrevistados son conocidos dentro del movimiento como «los pioneros». Estos miembros gozan de un estatus social alto dentro de la iglesia y son quienes aportaron los datos necesarios. A estos participantes se les informó debidamente de la finalidad de la investigación así como de la voluntariedad de la misma de manera verbal y por escrito.

Se llevaron a cabo entrevistas biográficas basadas en un guión previo que había sido elaborado por la investigadora principal. Este guión se le mostró a los entrevistados al inicio de la entrevista y sirvió como guía en el relato. La duración media de las entrevistas fue de entre 30-45 minutos y se realizaron un total de tres encuentros.

Tras su realización, se procedió a la trascripción y seguidamente a su análisis, poniendo en relación lo obtenido en el campo con lo evidenciado en la bibliografía. Se completó con las anotaciones del diario de campo de la investigadora principal donde se recogieron aspectos de comunicación no verbal, posibles preguntas, etcétera.

\section{RELATOS DE VIDA}

A continuación se presentan los relatos de vida tal y como han sido obtenidos con los cambios mínimos de corrección necesaria.

\section{Relato biográfico 1}

Lugar de nacimiento: Sevilla.

Sexo: Mujer.

Localidad de residencia: Dos Hermanas (Sevilla).

Familia: 5 miembros (matrimonio y 3 hijos).

Nací en Sevilla el 20 de diciembre de 1958, tengo 52 años. Vivo en Dos Hermanas con mi esposo y tres de mis hijos (tenemos cinco). Mi profesión es maquinista industrial, aunque hace algunos años que dejé de trabajar y me he dedicado a criar a mis hijos y atender a mi familia. De joven, estudié hasta la EGB, pero hacer algunos años me saqué el título de Graduado Escolar y después el de la ESO, y ahora estoy planeando hacer el bachillerato para adultos.

Nací en una familia humilde. Mi padres son sevillanos. Cuando yo tenía 10 meses, mi padre murió en un accidente de tráfico, atropellado por un camión, conducido por un hombre ebrio. Al quedarse viuda mi madre tuvo que criar sola a tres hijos pequeños: mi hermano E., mi hermana G. y a mí que era la más pequeña. Mi madre trabajaba mucho, tenía 2 o 3 trabajos a la vez, para poder mantenernos; incluso nosotros, siendo pequeños, la acompañábamos a limpiar los portales y las escaleras. Se esforzó mucho por llevarnos a buenos colegios, aunque eso significaba trabajar más. Mi madre también nos dio una educación religiosa, y asistíamos a misa cada semana, lo cual me gustaba, porque me gustaba escuchar las escrituras, aunque no me atraían las muchas imágenes que habían (me daban miedo), y no me gustaban los curas, aunque era fiel en comulgar y todo. 
A los 11 años, finales de 1969, sobre el mes de noviembre, tocaron nuestra puerta dos misioneros que trabajaban por esa zona, que quedaba cerca de la capilla. Hacía sólo unos pocos meses que llegaron los primeros misioneros a Sevilla, ya que la iglesia se estableció en mayo de ese año. Así fue como conocimos a dos élderes, un americano y un español criado en Uruguay, ambos servían sus misiones en Argentina, cuando les pidieron venir a España y extender sus misiones seis meses más para empezar la obra en nuestro país. Nos invitaron a mi familia y a mí a asistir un domingo a la iglesia, y fuimos a un chalet en el que vivían y donde se celebraban las reuniones en el salón. Al principio fue un poco raro, no había mucha gente, pero me gustó mucho todo. Nos invitaron a escuchar las charlas, y mi madre mi hermana y yo aceptamos, pero mi hermano no quiso. Tres meses después, las tres nos bautizamos; mi hermana se bautizo el 14 de febrero y mi madre y yo al día siguiente domingo 15 junto con la familia. Era por la tarde en una pila de plástico, grande, pero el agua estaba fría a pesar de que los misioneros se esforzaron por calentarla. Aquel fue un día especial para mí, me sentía como si toda mi vida hubiera esperado algo así, con once años entre en la Primaria, donde los niños aprendíamos sobre las cosas del evangelio, allí me llamaron a servir como directora de música, lo cual me preparó para servir después muchas veces para servir en este llamamiento.

Fueron unos años maravillosos, mucha gente se unió a la Iglesia y pronto tuvimos que cambiarnos para tener una capilla más grande. Nos fuimos a la calle Álvarez Quintero en el mismo centro de Sevilla. Tuvimos allí un grupo de jóvenes muy fuertes, que más tarde servimos misiones. En 1980 se recibió una carta de la presidencia de la Iglesia, el profeta entonces era Spencer Kimball, por aquel entonces teníamos otra rama en el Nervión y entonces mi presidente de rama, que era un misionero, me dijo que mi nombre aparecía y se me invitaba a servir en misión de tiempo completo, 18 meses, para las hermanas. No fue fácil porque mi madre no entendió el llamado y no aceptaba mi marcha, pero yo había orado y supe que era la voluntad del Señor. Salí el 2 de noviembre y regrese el 20 de marzo de 1982. Un tiempo del que no cambiaria nada de lo que viví.

Mi testimonio ha crecido mucho desde entonces, aun cuando decimos que los problemas parecen aumentar al bautizarnos dentro de la Iglesia. Para mí, 40 años después, me siento totalmente identificada con mi vida, se quién soy y a dónde me dirijo, el Señor me ha cuidado muy bien. Tuve el privilegio de sellarme en el templo de Suiza el 1 de septiembre de 1982 con el que era mi novio antes de servir ambos en la misión, de tener cinco maravillosos hijos que, a su vez, dos de ellos han sido misioneros por su propia decisión y se han sellado en el templo, tres de ellos formando familias eternas.

Ahora mismo sirvo como maestra de la Escuela Dominical de Adultos y como líder de la música en la Primaria a nivel de Estaca. Pertenezco a la Sociedad de Socorro y asisto a todas las reuniones siempre, a menos que este enferma. La obra genealógica es para mí más que sólo buscar nombres; me siento identificada con ellos y me encanta encontrar no sólo sus nombres sino también sus historias, cómo vivían y a qué se dedicaban.

\section{Relato biográfico 2}

Lugar de nacimiento: Sevilla, España.

Edad: 50 .

Sexo: Hombre

Localidad de residencia: Sevilla. 
Familia: 5 miembros (matrimonio y 3 hijos).

Ocupación: Sanidad.

Pertenezco a la Presidencia de la Estaca de Sevilla.

Yo conocí la Iglesia cuando tenía 21 años, ahora voy camino de los 51. Fue a finales del verano de 1981. Entonces yo estudiaba en la Universidad, ese día estaba solo en casa y llamaron a la puerta, eran dos chicos con camisa blanca, corbata, una chapita enganchada en el bolsillo de la camisa y se notaba a leguas que no eran españoles. Antes había visto otros por las calles, pero no tenía ni idea de quienes eran. Dos cosas me impulsaron a dejarlos pasar y escucharlos. Una porque me daba pena ver que, a pesar del calor que hacía, ellos estaban en la calle intentando compartir algo y que las personas les escucharan, se les veía cansados y algo sudorosos. La otra razón y creo que la más importante es porque percibí sinceridad e inocencia en su mirada.

El mensaje que compartieron conmigo en esa ocasión hablaba de José Smith y El libro de Mormón y me sorprendió en gran manera porque nunca antes oí hablar de ellos ni conocía su historia. Creo que tú ya la conoces y tal vez no deba extenderme. Pero sí debo decirte que no me resultó extraña porque en alguna ocasión yo había tenido los mismos sentimientos en cuanto a tanta diversidad de religiones, doctrinas y filosofías en el mundo. Yo era católico como mis padres, de pequeño estudié en un colegio de curas en Salamanca, los Salesianos, de los cuales tengo muy gratos recuerdos, siempre fui creyente $\mathrm{y}$, aunque en ese momento no practicaba ninguna religión, nunca perdí el sentimiento de la existencia de Dios y de Jesucristo como nuestro salvador.

Al terminar su mensaje ellos compartieron su testimonio conmigo y una escritura del Libro de Mormón, la cual se encuentra en el libro de Moroni, capítulo 10, versículos del 3 al 5, y me invitaron a poner en práctica lo que se indicaba en dicha escritura. Lo hice al poco de irse ellos, me arrodillé en mi habitación y elevé a Dios mis sentimientos y mi deseo de saber. Casi al instante de comenzar mi oración me invadió un sentimiento de paz, se me hizo un nudo la garganta y empecé a llorar como un niño. Los misioneros regresaron a casa dos días después, siguieron enseñándome durante unas tres semanas y me invitaron a bautizarme, lo cual acepté con deseos sinceros en mi corazón, y el 19 de septiembre de 1981 me bauticé. Hasta hoy han pasado muchos años y muchas, muchas experiencias que han fortalecido y fortalecen cada día más mi testimonio de que Jesucristo ha restaurado de nuevo su Iglesia por medio de un profeta. Serví como misionero cuando cumplí 23 años, me casé con mi esposa, la cual también sirvió como misionera, tenemos tres hijos maravillosos a los que hemos enseñado desde pequeñitos los principios del evangelio, pero que también han tenido que buscar su propio testimonio. Los dos mayores han servido como misioneros por dos años y mi hija desea hacerlo cuando cumpla los 21 . Los tres están ahora estudiando e intentando labrarse un futuro en la sociedad. Me siento el hombre más feliz de la tierra a pesar de los desafíos diarios y de mis imperfecciones, no sólo por la familia que tengo sino porque sé desde lo más profundo de mi corazón que Dios vive, que es nuestro Padre y que nos ama al punto de permitir que su hijo amado Jesucristo diera su vida por nosotros a fin de que pudiéramos volver algún día a su presencia mediante nuestra fidelidad a sus mandamientos y ordenanzas. Y porque sé que Él tiene un plan para cada uno de nosotros, y que ese plan incluye la posibilidad de vivir con nuestra familia por la eternidad si somos dignos. Mis padres no son miembros de la Iglesia 
y hace unos meses hablando con mi padre sobre Dios y Jesucristo descubrí algo que no sabía de él, me comentó: «Sabes hijo, yo sé que Dios existe porque cuando pienso en Él me dan ganas de llorar».

\section{Relato biográfico 3}

Lugar de nacimiento: Barcelona, España.

Edad: 51.

Sexo: Hombre.

Localidad de residencia: Dos hermanas, Sevilla.

Familia: Actualmente vivo con mi esposa y 3 de nuestros 5 hijos, ya que los dos varones ya están casados.

Nací el 26 de marzo de 1960 en la ciudad de Barcelona; mis padres, que nacieron en Sevilla, en el barrio de Triana, habían emigrado unos veinte años antes, aunque un año antes de nacer yo, volvieron a Sevilla, para casarse en la iglesia de Santa Ana. Yo soy el mayor de cinco hermanos, todos varones. Actualmente vivo en Dos Hermanas, Sevilla, con mi esposa y tres de nuestros cinco hijos, ya que los dos varones ya están casados. Mi actividad principal ha sido vendedor, agente comercial en diferentes empresas y como autónomo, aunque algunas veces lo he compaginado con otros trabajos. En cuanto a mis estudios, terminé $2^{\circ}$ de BUP y luego hice un curso de auxiliar administrativo, así como un curso de Técnico en electromecánica y varios cursos de empresa sobre marketing y ventas.

Después de mi nacimiento, mi familia permaneció viviendo en Barcelona, hasta que cumplí los cuatro años. En ese entonces comenzaron a despuntar las fábricas de colchones y mi padre, que era colchonero artesano, sufrió un duro golpe en su pequeña empresa familiar; como consecuencia de ello, tuvieron que volver a emigrar, ahora con una familia propia, formada por mis padres, mis dos hermanos menores y yo. En esta ocasión nos fuimos a vivir a África, a El Aaiún, la capital del antiguo Sáhara español. Allí mi padre invirtió todos sus ahorros en comprar una tienda de comestibles que mi abuelo le vendió -él era militar y tenía un negocio a medias con un amigo-, ya que él padecía una afección respiratoria que le obligó a marcharse a las islas Canarias, que tienen un clima más estable y benévolo que el desierto. Así que nos establecimos allí y seguimos viviendo allí hasta junio de 1975, cuando por motivo de la Marcha Verde, tuvimos que regresar a Sevilla deprisa y corriendo con una mano detrás y otra delante, después de once años de duro trabajo y dejando atrás un importante patrimonio que nos fue menospreciado y arrebatado. La parte positiva de estos acontecimientos, fue que al venir a la península, tuve la oportunidad de conocer la iglesia y a la que es mi esposa, mis mayores tesoros.

La forma en que contacté con la iglesia fue muy peculiar. Desde muy niño fui educado en la fe católica y practique la religión con regularidad, asistiendo a misa cada domingo por la mañana, hasta que tuve edad de ser monaguillo, después de hacer la primera comunión, cuando empecé a ayudar en misa diariamente, en la misa de la tarde, y los sábados y domingos en la de las 7 de la mañana y la de la tarde. Vivir en un país extranjero y con una mayoría religiosa diferente a la mía me ayudó a desarrollar un fuerte vínculo con la figura de Jesús, el Salvador; quien era un autentico héroe para mí, representando el valor de resistir con el amor, cualquier posible diferencia entre todos los seres humanos, quienes somos hermanos, hijos de un mismo Padre celestial. Estas experiencias, y el trato cercano con mi guía espiritual, un sacerdote que marco mi infancia y mi adoles- 
cencia, el padre O., despertaron en mi el deseo de servir a Dios y a mis semejantes, considerando incluso el ingreso en el seminario. Sin embargo, había algo que me tenía intranquilo y que mi buen amigo O. supo detectar y, gracias a su consejo, pude tomar la decisión acertada. Yo deseaba ser sacerdote pero, al mismo tiempo, quería tener mi propia familia y no encontraba como conciliar los dos deseos y, sus palabras me dieron cierta tranquilidad, aunque no eran una respuesta completa. Su consejo fue que yo debía casarme y criar a mi familia en la fe cristiana. A mi pregunta de por qué él no podía ser sacerdote y padre de familia, ya que era un ejemplo a seguir, me contestó que había tenido que escoger y que ese era un sacrificio que la Iglesia católica le demandaba para servir a Dios. Sinceramente no comprendía por qué y la respuesta no me satisfizo, pero la acepté esperando comprenderla algún día, y aplazando mi decisión a un momento futuro, no quería tener que escoger en ese momento, con sólo 15 años. En esa tesitura, estando muy unido a las actividades de la iglesia, y viviendo en una comunidad pequeña, donde todos nos conocíamos, fue como de repente todo nuestro esquema cambió radicalmente al tener que abandonar todo y salir huyendo a Sevilla. Al llegar a la península, me resultó muy difícil adaptarme a la forma de vida en una gran ciudad como Sevilla y a unas relaciones entre las personas, bastante más impersonales. Por todo ello, intenté volcarme en mi religión, pero, para mi sorpresa, la iglesia que yo había conocido en el Sáhara, donde servían misioneros y su vocación era muy evidente, no tenía nada que ver con lo que encontré al llegar aquí. De hecho, después de visitar las parroquias de Juan XXIII, Cerro del Águila, Su Eminencia, Gran Plaza y otras más, solo me pude identificar con Domingo, el párroco que servía en la iglesia de las Letanías, en las Tres Mil Viviendas del Polígono Sur. Allí sentí el mismo espíritu de vocación misional que había vivido en mis años anteriores, y allí me involucré en ayudar a la comunidad gitana y a los jóvenes con problemas de adaptación a la sociedad. Sin embargo, después de unos meses, me invadió un sentimiento de insatisfacción, como si me faltara algo o como si hubiera perdido algo. Fue con ese sentimiento que me marché a Málaga el verano de 1976, a casa de una amiga del Aaiún, una buena amiga cuya familia me trataba como otro hijo, y yo necesitaba recuperar algo que no sabía cuándo lo había perdido ni tampoco dónde. Me invitaron a pasar unos días con ellos y, un sábado por la tarde, mientras nos dirigíamos a una discoteca cerca del puerto de Málaga, íbamos con mi amiga y su primo, al pasar por la entrada a la calle Larios, en la acera, junto a la oficina del Banco de Santander, habían colocado una pancarta con una foto de Jesucristo en un lado y otra de una familia al otro lado. Junto a la pancarta estaban unos jóvenes muy bien vestidos con traje y corbata, que paraban a la gente en la calle para hablarles señalando con el dedo a la pancarta. Inmediatamente que vi la foto de Jesucristo, mi corazón palpitó y deseé saber qué decían de Él esos jóvenes. Entonces le pregunté a mi amiga quiénes eran. Me dijo que eran unos americanos que pertenecían a otra iglesia, los mormones. Le dije si podíamos pararnos a escuchar lo que decían, pero llevábamos prisa para llegar a la discoteca, donde habíamos quedado con otros amigos, así que me quedé con las ganas, pues yo había sentido el impulso de acercarme a ellos y hablarles de lo que significaba para mí el Salvador. Al regresar a Sevilla, en septiembre empecé a estudiar Auxiliar administrativo en la Academia Gorka, que se encontraba en la plaza San Francisco, a la espalda del ayuntamiento. Pasaron varios meses, hasta que un día, un compañero de la academia me dijo: «Oye, acaban de pararme en la calle unos americanos que son misioneros mormones y me han invitado a asistir el domingo a unas reuniones que tienen aquí detrás, en un piso que llaman capilla; yo no quiero ir solo, ¿quieres acompañar- 
me tú?» En seguida supe que se trataba de los mismos que vi en Málaga, y me entusiasmó la idea de saber que también estaban en Sevilla, pero la compañía de mi colega no era muy grata, así que rechacé acompañarle, aunque me fastidió mucho perder otra ocasión para escucharles. Pasó ese año, y mi insatisfacción seguía siendo mi mayor problema, me sentía como un marciano, sin que nadie compartiera mis ideas y mis anhelos. A principios del año 1977, sin saber qué norte seguir, me volqué en buscar una guía espiritual, preparándome para la celebración de la Semana Santa, practicando un retiro espiritual particular, en mi propia casa, ya que la excesiva adoración a las imágenes en la Semana Santa, no concordaban con mi educación religiosa en El Aaiún, donde se trabajaba con las personas, edificando una relación íntima y personal con Jesús, en lugar de dirigirnos a una multitud de imágenes que, me parecía que diluían el concepto central y único del Salvador. Así seguí, en ese espíritu de búsqueda, hasta que a finales del verano unos misioneros empezaron a trabajar en mi barrio, donde vivía con mis padres y hermanos, en el Polígono de San Pablo. Uno de ellos era bajito con gafas y muy tímido, pero era un gran líder, de hecho era el presidente de la rama en aquel tiempo. El otro era un fornido luchador de lucha grecorromana, acababa de llegar a España hacía solo unas semanas y aun no conocía mucho el idioma, pero era la atracción de todos los niños del barrio, entre ellos mi hermano pequeño A., que tenía unos 5 años y cuando pasaban por allí los misioneros, le pedían que les dijera la hora, para escuchar su acento americano. Luego les pedía que lo levantara y el élder extendía su antebrazo, donde se colgaban los niños, y los levantaba muy alto, lo cual les encantaba y formaban corrillo en grupos alrededor de ellos, para guardar turno mientras los subía a todos uno a uno. Después de algunos días, mi hermano A. les dijo a los élderes: «Oye, tenéis que ir a mi casa y hablar con mi hermano J.»; sorprendidos le preguntaron donde vivía y mi hermano les indicó la dirección de nuestra casa, a lo que ellos contestaron que ya habían tocado nuestra puerta. Al día siguiente, se repitió la misma escena y mi hermano les dijo: «No habéis ido a ver a mi hermano J. Tenéis que ir a mi casa que el os escuchará». Para nada había insinuado algo parecido ni a mi hermano ni a nadie de mi familia, aunque todos sabían de mis inquietudes religiosas. Sin embargo, esta vez los líderes pensaron que tal vez deberían tocar otra vez, así que subieron a mi casa y volvieron a llamar a la puerta. Al abrir mi madre, ellos le dijeron que querían compartir un mensaje con la familia; a lo que mi madre respondió de esta manera: «Lo siento, no puedo atenderos porque estoy preparando la comida para mi esposo y mis hijos que llegan del colegio, pero si venís mañana por la mañana, seguro que mi hijo Jordi os escucha». Yo no había referido nada sobre mis experiencias anteriores con los mormones, así que cuando luego me enteré de todo esto, fue una confirmación de que el Señor había preparado el camino para que llegara a conocer su iglesia restaurada. Los misioneros quedaron en volver al día siguiente, y tal como dijeron, al llamar a la puerta de mi casa esa mañana, acudí yo a responder y, al abrir la puerta me encontré una estampa que jamás olvidaré. Dos jóvenes de unos 19 o 20 años -yo tenía entonces 17 años-, vestidos pulcramente con sus trajes y sus camisas blancas y corbatas, rubios con ojos claros y hablando con un acento extranjero - destacando la diferencia de altura que había entre ellos dos- me preguntaron: «Somos representantes de Jesucristo y traemos un mensaje que nos gustaría compartir con usted». De todas las formas de despertar mi interés, sin duda alguna fueron inspirados a utilizar la que de verdad haría abrir mi corazón. Jesucristo era mi ídolo y cualquier mensaje que tuviera que ver con Él, era importante para mí, así que los invité a pasar y me enseñaron el mensaje de la restauración del evangelio 
con la primera visión del joven José Smith. Aunque era la primera vez que lo escuchaba, a medida que relataban la historia de ese maravilloso acontecimiento, asentía con la cabe$\mathrm{za}$, mientras en mi mente se repetía el pensamiento: «Claro, eso es» $\mathrm{y}$, al mismo tiempo, sentía que mi corazón se henchía de gozo al escuchar semejante mensaje. Así, invitaron a asistir a la iglesia el domingo y allí confirmé que me encontraba en el lugar que tanto había estado buscando en los últimos meses. Unos meses después, me fui voluntario a la mili, para poder hacer una misión pronto y, en noviembre de 1980, salí para servir como misionero de tiempo completo en la misión de España-Madrid .

Después de más de 33 años de ser miembro de la iglesia, he tenido oportunidad de servir en muy diferentes llamamientos, entre ellos, he sido presidente de rama en tres ocasiones y he servido como consejero de los dos presidentes de la estaca, además de servir en el consejo de la estaca desde hace varios años. Nunca he dejado de asistir a las reuniones de la iglesia, excepto por enfermedad. Siempre he tratado de participar activamente en mi comunidad; actualmente soy el vicepresidente de un partido político, el CDS, en mi localidad y estoy involucrado en ayudar a resolver los problemas que nos afectan a todos en nuestro diario vivir. En cuanto a la historia familiar, es algo que nuestra familia ha tratado de inculcar a todos como una tradición y al tiempo como un deber. Algunas de las experiencias más especiales las hemos vivido trabajando en la búsqueda de nuestros antepasados, y es un placer hacerlo.

\section{Relato biográfico 4}

Lugar de nacimiento: Sevilla.

Edad: 37.

Sexo: Hombre.

Localidad de residencia: Málaga.

Nací en Sevilla y desde muy pequeño he viajado por toda la zona norte de España; entre los lugares en los que he vivido están Burgos, Madrid, Miranda del Ebro. Debido al oficio de mi padre que era ferroviario en RENFE tuvimos que mudarnos a la que sería nuestra residencia definitiva en Málaga, capital donde llevo más de 25 años residiendo. Mi familia esta muy arraigada a las tradiciones locales. Mi abuelo fue miembro fundador y hermano mayor de la casa Hermandad de El Cautivo de las Cabezas de San Juan, lo cual hace que mi fe esté todavía arraigada en el catolicismo debido a los lazos familiares y a los miembros familiares, incluido yo. Mi padre murió en el año 2000 dejando en nuestros corazones un amargo y triste dolor y ello trajo mi pérdida de pasión por la fe. Yo jamás pensé en unirme en ninguna denominación cristiana, pues creo que Dios actúa de forma libre y mística y no se puede dar explicación a lo que no lo tiene. Iba por la vida buscando respuestas en cuanto a la fe en Cristo nuestro Señor, pues Él es un padre y como tal siempre anda escuchando a quienes se le pide desde el corazón desde la sencillez y la humildad. Así que eso hice: oré para encontrar respuestas firmes y contundentes y mi sed de conocimientos hizo que Dios pusiese a dos líderes varones un día de 2012, en pleno verano, cuando atravesaba un mal momento familiar y personal. Aparecieron subiendo al autobús y se sentaron uno a mi lado y otro al otro y empezaron a hablarme de su fe y de como ellos conocieron a Cristo nuestro señor por medio de señales y revelaciones, incluso en nuestros días. Y durante el viaje de vuelta a Málaga me fueron comentando su historia personal, sus experiencias personales y me invitaron al templo. Me dije ¿qué tengo 
que perder? Y fui. Fue hermoso haber conocido a una pareja de misioneros; lo que me gusto de ellos es el trato que recibí de ellos, que fue maravilloso y hermoso, el tiempo que pasé con un grupo que se preocupó de mi desde el primer día hasta mi bautismo y confirmación. Por eso decidí conocer a esta rama cristiana y experimentar un nueva forma de conocer a Dios y me quede impresionado de tanta rectitud. ¡Parecía un desfile militar todos de negro! pero lo que me hizo ser uno más de ellos fue su gran amor hacia mí. Cuando me encontré a los misioneros jamás pensé que el regalo que ellos me dieron me cambiase la vida y, tras seguir sus consejos, jamás pensé que realmente un insignificante libro me cambiase mi vida personal de forma tan drástica como lo hizo. La primera vez que lo leí me pareció que era una hermosa historia de amor para los hombres de parte de Dios. Ahora que lo voy leyendo poco a poco es como leer el libro de La Historia interminable, pero cuando lo estudias en profundidad con humildad y sencillez en tu vida, tu propia vida cambia drásticamente de una forma asombrosa y no hay palabras para describir tal experiencia espiritual en mi vida. Animo a leerlo y aseguro que les cambiara su vidas para siempre. Para mí, personalmente, me la sigue cambiando cuando menos lo esperas, pues es así como Dios actúa en quienes tienen fe humildad y sencillez de obras y de corazón, llevando consigo una fe cada vez más y más fuerte en quienes confían en Nuestro Padre celestial y llevan el evangelio en su día a día y dentro de sus vidas cotidianas. Así no hay un día que no piense de qué manera puedo cambiar yo mi vida, día a día, y no pensé jamás que un simple libro me cambiaria la vida de esta forma tan bestial, por explicarlo de alguna forma. Venía de un mundo materialista que sólo pensaba y luchaba para sí mismo y no para nadie mas; mundo que no piensa y actúa de otra forma que no sea más que para engullir todo lo que pilla por su camino, sin más miramiento que uno mismo. Leer El Libro de Mormón supuso un gran cambio en mi vida y un giro de 180 grados en mi forma de vivir mi vida y saber que yo le importo a Dios. Me sacó del abismo infernal en el que me había metido sin saberlo y puedo decir que gracias a Dios tuve la oportunidad de redimirme, gracias a El libro de mormón, que me dio nuevas expectativas y una nueva forma de ver la vida y de creer en Jesús, como Él quiso realmente. Desde muy pequeño he tenido a Jesús muy a dentro de mí, criándome en la cultura cristiana católica apostólica y romana, desde los siete hasta los quince. He compartido mi credo con todo el mundo, siendo consciente de que algún día encontraría mi camino entorno a la verdadera vida en Cristo Jesús Nuestro Señor. Mis abuelos son muy arraigados a las tradiciones locales y he vivido en primera línea la pasión de Cristo de mano de mis abuelos maternos, pero no fue hasta los 20 o 25 años cuando empecé a sufrir la realidad de la tan querida tradición católica, la iglesia que un día creí que era la única iglesia desaparece tras comprobar en mis carnes la cruda realidad que escondía el Vaticano muchos de esos «párrocos»o «sacerdotes» o como lo queramos llamar, violaban a muchos chicos menores. Ahí se acabó para mí el ser católico, desde entonces he ido vagando espiritualmente en buscar respuesta a mis interrogantes espirituales e incógnitas personales. Gracias al encuentro de dos misioneros pude encontrar respuestas a mi sed de conocimiento en Dios Nuestro Señor. En el año 2012 encontré justo las respuestas a esas incógnitas que me hacía sobre la verdadera fe en Cristo Jesús. 


\section{ANÁLISIS Y RESULTADOS}

Se llevó a cabo un análisis «vertical» de cada uno de los relatos y uno «horizontal» del conjunto de los relatos. De ambos análisis se extrajo la parte común a todos siguiendo el concepto «saturación de información por representatividad». Esto último señaló el final del registro. Tras este análisis de estos relatos y junto con la revisión de la bibliografía, se expone a continuación un acercamiento a la historia de la implantación del movimiento en Sevilla.

Con el estallido de la Guerra Civil llega la represión; el nacional-catolicismo arrasa con los avances conseguidos en materia de libertad religiosa, relegando a las minorías al ostracismo y la clandestinidad. Esta situación perdurará hasta prácticamente los años sesenta, en los que el desarrollo económico obliga a replantearse la posición con respecto a la religión, y por ello suavizar la política en materia religiosa. Esto supone el caldo de cultivo para la llegada de la Ley de libertad religiosa de 28 de junio de 1967, en cuyo artículo primero señala: «el ejercicio del derecho de la libertad religiosa, concebido según la doctrina católica, ha de ser compatible en todo caso con la confesionalidad del Estado español proclamada en sus leyes fundamentales»».

No obstante, ya en la clandestinidad convivían comunidades religiosas no católicas que negaban la uniformidad católica del país. En el caso de Sevilla, desde 1963 existen informes que registran la llegada del grupo militares estadounidenses miembros de la iglesia a la base militar de Morón de la Frontera (Sevilla) y en mayo de 1965 este llamado grupo Morón-San Pablo cuenta con 47 personas, con una asistencia del 61\% a la Reunión Sacramental (López, 2014).

Pero, en base a los relatos, puede decirse que la historia de los Santos de los Últimos Días en Sevilla comienza en 1969 con el alquiler de un local en la calle Cea Bermúdez para ser centro de reuniones. Era un chalet, que hasta entonces había servido como domicilio particular, en el que comienzan a producirse las primeras reuniones. En octubre de 1970 el entonces presidente de la iglesia visita varias poblaciones de la provincia de Sevilla y unos meses más tarde se reúne en Sevilla con el dueño del local situado en la calle Álvarez Quintero, 24, para alquilarlo como lugar de reuniones. Se firma un contrato para empezar las reuniones el 1 julio 1971. En este caso, se trataba de un piso de tres plantas. Y aquí se reúnen estos miembros hasta que, en mayo de 1977, dado el crecimiento del número de miembros, la Rama de Sevilla se divide en dos:

- Rama Sevilla Centro (Rama 1), cuyo Centro de reuniones sigue siendo el piso situado en el número 24 de la calle Álvarez Quintero.

- Rama Sevilla Nervión (Rama 2), que celebra sus reuniones en un local en la calle Tomás Murube. 
En este tiempo, surgen 2 nuevas ramas:

- Rama 3, con centro de reuniones en un local en la calle Ingeniero la Cierva.

- Rama 4: que comparte el centro de Reuniones con la Rama 2, en la calle Tomás Murube.

Así perviven ambos centros de reuniones hasta que en 1980, la Iglesia SUD adquiere en propiedad un local en la calle Santo Domingo de la Calzada. La Rama Sevilla Centro continuó en la calle Álvarez Quintero, hasta 1978, que se trasladan a un local (que fue un garaje) en la calle Almadén de la Plata. Finalmente, las Ramas 3 y 4 se reordenan con la Rama 2, quedando finalmente las Ramas 1 y 2 en Sevilla. Estarán cuatro años acudiendo a sus reuniones en este local, hasta que en 1983, la Iglesia adquiere una segunda propiedad, esta vez en la calle González Cuadrado (Núcleo Monte Sión). Ambas propiedades, la de la calle Santo Domingo de la Calzada y la de la calle González Cuadrado, son por las que la iglesia obtiene la permuta y construye el actual Centro de Reuniones de Sevilla, en Ronda Norte, que termina uniendo a las dos ramas.

Entretanto, en abril de 1970 tendrá lugar una conferencia en Sevilla contando con aproximadamente 90 asistentes entre los que estaban miembros y visitantes. En noviembre de este año eran ya 46 el total de misioneros en España, doce de los cuales estaban en Andalucía. A partir de aquí se trabajará en dar a conocer la iglesia a los dirigentes políticos y población en general, con actuaciones como las de «Los Salt Lake City» o programas musicales como «Una noche de hogar inolvidable» en 1972. Tras la muerte de Franco, en 1976 la Misión España queda dividida en 3 misiones: España-Madrid, España-Barcelona y España-Sevilla, cambiando esta última su denominación por la de España-Málaga, que engloba las estacas de Sevilla, Cádiz, Granada, Elche y Cartagena (López, 2014).

\section{CONCLUSIONES}

Como se ha visto, los miembros de Sevilla comenzaron en domicilios particulares, permaneciendo invisibles a la sociedad durante años, hecho motivado por el momento en el que se encontraba la sociedad española en lo que a libertades religiosas se refiere.

La elección de las historias de vida como método para acercarnos a una realidad como la de los movimientos religiosos se presenta como la más idónea para conocer este acontecimiento social desde la visión de los protagonistas, permitiendo además conocer como este hecho social influía en sus vidas.

Los inicios de un movimiento religioso como el de los Santos de los Últimos Días, en un momento histórico como el que se ha descrito, muestran la realidad 
de un país donde empezaba a evidenciarse la pluralidad religiosa. El conocimiento del caso sevillano de la mano de estos informantes ha supuesto no sólo el conocimiento del recorrido histórico, sino también de las vivencias de los miembros que participaron en la creación de esta comunidad en Sevilla.

\section{BIBLIOGRAFÍA}

ACEves LozAnO, J.: «Práctica y estilos de investigación en la historia oral contemporánea», Historia y Fuente Oral, 12, Barcelona, 1994, pp. 143-150.

Arjona Garrido, A., Checa Olmos, J. C.: «Las historias de vida como método de acercamiento a la realidad social», Gazeta de Antropología, 14, 1998, artículo 10 .

Briones, R. (dir.): ¿Y tú (de) quién eres? Minorías religiosa en Andalucía, Fundación Pluralismo y convivencia, Barcelona: Icaria Editorial, 2010.

HinCKLEY, G.: La verdad restaurada: una breve historia de la Iglesia de Jesucristo de los Santos de los últimos días, Salk Lake City: Corporation of the President of the Church of Jesus Christ of Latter-day Saints, 1969.

López, F.: La Iglesia de Jesucristo de los Santos de los últimos Días. Implantación, desarrollo en España y estudio comparativo con otros países europeos, Tesis doctoral, Universidad Complutense de Madrid, 2014.

\section{Agradecimientos}

Quiero agradecer la colaboración de los informantes, así como a todos los miembros de la Iglesia de Jesucristo de los Santos de los Últimos Días en Sevilla que han participado, sin cuya colaboración desinteresada esta investigación nphabría sido posible. 